\title{
ESTETIK TARI SINING PADA MASYARAKAT GAYO KABUPATEN ACEH TENGAH
}

\author{
Magfhirah Murni Bintang Permata ${ }^{1^{*}}$, Rika Wirandi2* $^{*}$, Berlian Denada $^{3^{*}}$ \\ Jurusan Seni Pertunjukan \\ Institut Seni Budaya Indonesia (ISBI) Aceh \\ Jl. Transmigrasi, Gampong Bukit Meusara, Kec. Kota Jantho,Kab. Aceh Besar, Kode Pos 23911 \\ Aceh. Indonesia \\ Email:firafatir04@gmail.com,rikawiranda@isbiaceh.ac.id,berliandenada@isbiaceh.ac.id
}

\begin{abstract}
Abstrak
Penelitian Nilai Estetik Tari Sining padamasyarakat Gayo bertujuan mendeskripsikan koreografi dan nilai estetik Tari Sining Koreografi Tari Sining menupakan salah satu daya Tarik yang memiliki nilai estetik lebih sehingga tarian ini sebelumnya pemah punah, hingga pada akhimya dilestarikan kembali melalui upaya revitalisasi dan menjadi warisan budayadaerah Aceh. Dengan memiliki nilai estetik koreografi yang lebih dan dapat tergambar melalui gerakan yang dihasilkan sehingga dapat menyatu dengan konsep kehidupan masyarakat tarian ini dapat di terima dengan baik oleh masyarakat. Analisis koreografi Tari Sining menggunakan konsep koreografi Sumandiyo Hadi. Analisis nilai estetik menggunakan konsep nilai estetik menurut The Liang Gie, yang didukung oleh konsep ciri-cin sifat benda estetikoleh Monroe Beardsley, dan konsep pengungkapan nilai-nilai kehidupan dalam karya seni oleh De Witt H. Parker. Penelitian ini menggunakan metode penelitian kualitatif dengan pendekatan estetik. Teknik pengumpulan data yang digunakan adalah observasi, wawancara dan studi pustaka. Hasil penelitian menunjukan bahwa Tari Sining memiliki nilai estetik karena dari sudut pandang yang mampu dis erat oleh inderawi memiliki nilai bentuk dan dari sisi manapun mengungkapkan nilai-nilai kehidupan pada mas yarakat Gayo menjadikan Tari Sining sebagai salahs atu ritual dari budaya dan tradisi masyarakat pada masanya.
\end{abstract}

Kata Kunci: estetik, tari sining, gayo.

\begin{abstract}
Research on the Aesthetic Value of Sining Dance in the Gayo community aims to describe the choreography and aesthetic value of the Sining Dance. The choreography of Sining Dance is one of the attractions that has more aesthetic value so that this dance has previously been extinct, until it is finally preserved again through revitalization efforts and becomes the cultural heritage of Aceh. . By having more choreographic aesthetic value and can be illustrated through the resulting movements so that it can be integrated with the concept of community life, this dance can be well received by the community. The choreography analysis of Sining Dance uses the choreography concept of Sumandiyo Hadi. Aesthetic value analysis uses the concept of aesthetic value according to The Liang Gie, which is supported by the concept of the characteristics of aesthetic objects by Monroe Beardsley, and the concept of expressing the values of life in works of art by De Witt H. Parker. This research uses qualitative research methods with an aesthetic approach. Data collection techniques used were observation, interviews and literature study. The results showed that Sining Dance has aesthetic value because from the point of view that the senses are able to nibble it has a form value and from any side reveal the values of life in the Gayo community making Sining Dance a ritual or ritual of the culture and traditions of the people of its time.
\end{abstract}

Keywords: aesthetic, sining dance, gayo.

\section{PENDAHULUAN}

Tari Sining sebagai salah satu wujud hasil karya ciptaan manusia yang dimiliki oleh mas yarakat Gayo dengan nilai keindahan di dalamnya. Keindahan merupakan salah satu mutu pada sebuah seni sehingga berpengaruh pada kesenian itu agar tetap ada. Bertahan tanpa tergerus oleh perkembangan zaman, semakin tinggi nilai estetika seni, maka dan semakin diminati oleh masyarakat. sehingga eksistensinya mengalami kemajuan dan dapat dilihat melalui proses bagaimana seni tercipta indah.

Proses seni tercipta "indah" dapat dilihat melalui tiga as pek yaitu dilihat melalui bentuk atau wujud, isi, dan penampilan, sehingga dapat dirumuskan masalah dalam penelitian ini yaitu bagaimana nilai keindahan Tari Sining dengan kajian pokok dilihat melalui bentuk pertunjukan yang terdiri dari aspek pokok dan aspek pendukung. Isi terdiri dari gagasan/ ide, 


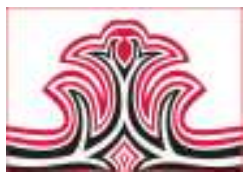

suasana, dan pesan. Penampilan terdiri dari bakat, keterampilan, dan sarana atau media.

Tari Sining pada dasarnya menggunakan bentuk gerak yang mengambarkan gerakan mimitif seeokor bunung sering disebut oleh mas yarakat sebagai manuk uwo. Gerakan yang dilakukan didominasi oleh gerakan kaki berbentuk pararel (Wawancara dengan Petriana Kobat, di Takengon. 2020). Bentuk-bentuk gerak yang disajikan tidak-lah sama dengan gerak sining yang terdapat pada Tari Guel. Ciri khas gerak yang dimiliki Tari Sining menjadi daya tarik yang kuat sehing ga Tari yang dahulunya pernah terhenti, saat ini kembali muncul dan dapat diterima baik oleh masyarakat. Hal ini menjadi salah s atu bukti bahwa Tari Sining memiliki nilai estetika sehingga mampu diterima baik oleh masyarakat dan pemerintah daerah. Selain itu, juga mampu menjadikan tarian ini sebagai salah satu Warisan Budaya Tak Benda (WBTB) pada tahun 2020.

Bentuk, gaya dan gerak Tari Sining yang berbeda antara Tari Sining dan gerak sining yang ada pada Tari Guel menjadikan beberapa gerakan sining susah untuk dilakukan oleh penarinya karena mas ih terbawa oleh kebiasan gerak yang dilakukan pada Tari Guel. Hal tersebut menyebabkan penari mengalami kesulitan dalam mengolah gerak. Menurut Simatupang, kondisi tubuh yang sudah dibiasakan pada teknik dan bentuk gerak merupakan salah satu pembatas untuk menerima teknik dan bentuk yang lainnya (Simatupang, 2013).

Pada mulanya, Tari Sining ditarikan di atas rumah pangung/ rumah adat mas yarakat gayo. Dimulai dari teras rumah hingga tangga menjadi tempat pertunjukannnya, pada sejarahnya ditarikan di atas keting gian 8-12 meter dari permukaan tanah, tepat di atas kerangka rumah adat.

Pada saat ini, teknik gerak yang dilakukan lebih rendah di atas ketinggian dua setengah sampai tiga meter. Perubahan teknik bentuk gerak, menyebabkan tarian ini memiliki kemudahan untuk ditarikan di atas pentas dan memilki kemantapan estetis sendiri saat dipertunjukan, dan dapat dilakukan oleh penari. Hal itu menyebabkan peneliti melakukan penelitian. Ada dua rumusan masalah dalam penelitian ini, di antaranya: pertama, bagaimana koreografi Tari Sining pada Sanggar Kuta Dance; kedua, bagaimana nilai estetik Tari Sining pada Sanggar Kuta Dance.
Gorga : Jurnal Seni Rupa

Volume 09 Nomor 02 Juli-Desember 2020 p-ISSN: 2301-5942 | e-ISSN: 2580-2380

Analisis koreografi Tari Sining menggunakan landasan teori elemen-elemen koreografi menurut Sumandiyo Hadi. Elemen-elemen tari terdiri dari: judul tari, tema tari, tipe atau jenis tari, mode atau cara penyajian, penari, gerak, ruang, musik tari, tata rias dan busana, properti, serta tata cahaya (Hadi, 2003). Elemenelemen koreografi tersebut digunakan untuk menganalisis koreografi Tari Sining pada masyarakat Gayo.

\section{Nilai Estetik}

Landasan teori yang digunakan untuk men g a nalis is nilai estetik Tari Sining adalah teori nilai estetik dari The Liang Gie. Nilai estetik dalam sebuah karya seni terdiri dari bentuk yang memiliki nilai bentuk (inderawi), dan isi yang mampu mengungkapkan nilainilai kehidupan (Gie, 1976). Nilai bentuk Tari Sining Pandhelori dianalisis dengan tiga ciri-ciri sifat benda estetik yang dikemukakan oleh Monroe Beardsley, yaitu kesatuan (unity), kerumitan (complexity), dan kesungguhan (intensity) (Kartika, 2007). Nilai-nilai kehidupan yang terdapat dalam Tari Sining dianalisis dengan teori milik De Witt H. Parker. Menurut Parker, nilai- nilai kehidupan sebagai isi sebuah karya seni dapat dirasakan melalui lambang sense, yang dibentuk dari med iu m ungkap y ang digunakan. Lambang sense itu membentuk sebuah rasa, dari rasa itu akan menuntun imajinasi penghayat untuk menangkap nilai-nilai kehidupan (Parker, 1979).

\section{METODE PENELITIAN}

Penelitian ini menggunakan metode penelitian kualitatif, dengan pendekatan es tetik. Teknik pengumpulan data yang digunakan adalah observasi, wawancara dan studi pustaka. Observasi yang dilakukan adalah observasi langsung partisipasi, dengan mengamati langsung. Wawancara dilakukan oleh peneliti kepada narasumber pemilik Sanggar Kuta Dance, Aceh Tengah, sebagai sanggaryang pemah merekonstruksi Tari Sining.

Studi pustaka dilakukan peneliti dengan membaca beberapa buku. Buku-buku itu dibaca dan kemudian informasi dan hal penting dikutip menunut kebutuhan. Referensi yang dikumpulkan dalam studi pustaka sangat berperan dalam memilih fokus penelitian ini

Jenis penelitian yang dilakukan oleh peneliti bersifat deskriptif-kualitatif. Penelitian kualitatif penelitian yang bermaksud untuk memahami fenomena tentang apa yang dialami subjek penelitian mis alnya, persepsi, motivasi, tindakan, dll. Secara holistik, dan dengan cara deskripsi dalam bentuk kata-kata dan bahasa pada saat konteks khusus yang alamiah dan dengan

\section{KAJIAN TEORI}

\section{Analisis Koreografi}




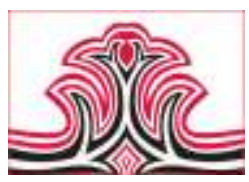

memanfaatkan berbagai metode ilmiah (Moleong. 2008).

\section{HASIL DAN PEMBAHASAN}

1.Hasil

\section{1). Koreografi Tari Sining}

Bentuk gerak non-representatif yaitu bentuk gerak yang maknanya sulit untuk dipahami, namun memiliki kekuatan ungkap yang bisa dirasakan. Gerakangerakannya sangat dinamis dan heroik. Tidak sembarang orang dapat melakukannya tarian yang dilakukan di atas bere umah. Dahulu, penari melakukan puasa terlebih dahulu kemudian baru dapat menari (Manan, 2017). Di dalam Tari Sining sangat identik sebagai bentuk komunikasi gerak dan respon ekspresi sebagaimana pengadaptasian dari gerak burung wo dan ungguk. Antara penari memiliki sinergi gerak saling mendukung dan berimbang seolah saling menjaga keseimbangan, dan kerjasama yang baik.

Penari dalamkarya tari merupakan pendukung utama yang menentukan keberhasilan atau kemantapan sajian tari (Prihatini, et.al. 2007). Penari dalam sebuah karya tari dapat dirinci menjadi jumlah penari dan jenis kelamin. Tari Sining saat ini dis ajikan dalam sebuah pertunjukan dilakukan oleh dua orang penari lakilaki dewasa. Tiap penari dalam Tari Sining seolah mengambarkan dan memiliki peranan, sebagai manuk uwo dan manuk ungguk.

Tari Sining menggunakan kaki pararel dan mujingket (jinjit), dengan sikap wajah tegas namun mengayomi. Gambaran pemimpin yang berwibawa. Dengan arah gerak yang mengarah ke sebelah kiri mengikuti rotasi bumi yang melambangkan menjaga keseimbangan, dan diartikan sebagai menjaga keseimbang an pemimpin yang berada di dalam rumah.

Munete adalah gerakan yang dilakukan saat menaiki anak tang ga dilakukan dengan kaki ses ekali mujingket (jinjit), dan gerak luncet adalah gerak terumit yang dilakukan dalamtarian ini sikap badan yang digunakan dari membungkuk hingga melompat ke atas properti tari yang telah dibuat dari sembilah papan yang memiliki tinggihing ga dua seteng ah sampai tiga meter. Sedangkan kepur nungguk adalah gerak mengibas kain.

Motif gerak itu ada yang merupakan motif gerak penghubung dan motif gerak pengulangan. Motif gerak penghubung adalah motif gerak yang digunakan un tuk menghubungkan dari motif gerak satu ke motif gerak yang lainnya. Motif gerak pengulangan adalah
Gorga : Jurnal Seni Rupa

Volume 09 Nomor 02 Juli-Desember 2020

p-ISSN: $2301-5942$ | e-ISSN: 2580-2380

motif gerak yang dilakukan lebih dari satu kali (diulang) dalam sebuah sajian karya tari (Hadi, 2003).

Di dalam motif gerak Tari Sining terdapat motif gerak penghubungdan motif gerak pengulangan. Motif gerak penghubung pada Tari Sining adalha kepur nunguk. Motif gerak pengulangan jenyong, pantik, geritik, jingket, nete, luncet, sini kaso, jejak bere, tangak bere, sining, temabur 145ngin, kepur nunguk, tari nuwo, ayun, gerdak, tinyo, gelani manuk, rajah/tebes, poroh.

Ruang dalam sajian tari dapat dibedakan menjadi dua, yaitu ruang pentas dan ruang gerak. Ruang pentas adalah tempat yang digunakan penari dalam menyajikan karyanya. Ruang gerak adalah ruang yang terbentuk karena adanya gerakan yang dilakukan oleh penari. Ruang gerak dapat dibagi menjadi beberapa bagian y aitu ruang motif gerak, level, formasi, dan pola lantai (Hadi, 2003).

Motif gerak Tari Sining memiliki ruang atau volume besar (luas), karena disajikan dalam bentuk gerak tari laki-laki dan kepakan burung. Level yang digunakan pada Tari Sining adalah level rendah dan level tinggi. Kedua penari Tari Sining menggunakan level yang selalu sama, level rendah digunakan padabentuk gerak kaki munete, geritik. Selain itu, penari juga menggunakan level tinggi.

Bentuk musik Tari Sining pada dasamya sama dengan bentuk tari Gayo pada umumnya terdapat nada, syair, dan sebuku. Notasi y ang digunakan adalah notasi gaya Gayo, namun rasa garap yang muncul adalah keselaran musik yang dimainkan oleh beberapa alat mu sik tradisi Gayo yang tergolong hampir lengkap, yaitu suling ines (suling bambu), uluhsiring, (susunan bambu dengan tangganada), gegedem, rapai, bantal didong, gerantung, uluhnaru, teritit, serta teganing. Hal itu disebabkan dalam proses revitalisasi koreografer dan komposer mencoba mengangkat dan menyatukan musik daerah gayo. Struktur sajian tari yang digunakan dalam Tari Sining, sesok, jenyong, ayun langkah dan tari uwo, nete, sining, poroh dan rajah/tebes, jingket, kepurnunguk, luncet, gertik, pantik, dan jenyong.

\section{2). Tata Rias Busan}

Tata rias Tari Sining adalah corrective makeup, dengan penebalan pada warna alis, kelopak mata, tulang pipi, hidung, dan bibir, yang memberi kesan tegas dan tampan (Mangundiharjo, 2014a).

Kostum yang digunakan pada Tari Sining dengan mengunakan kostum baju tradisi adat Gayo. yaitu, 


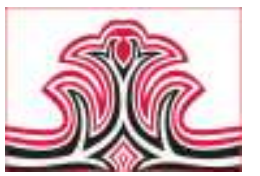

kain kerawang dan mengunakan kain ulen-ulen sebagai kostum sekaligus properti. mengunakan tangang ringit/ kalung yang terbuat dari uang logam, gelang kaki, mengunakan gelang kaki, baju dan celana lengan panjang, menggunakan ikat pinggang bermotif kerawang, disebut dengan kerawang, bulang kerawang, dan opoh ulen-ulen.

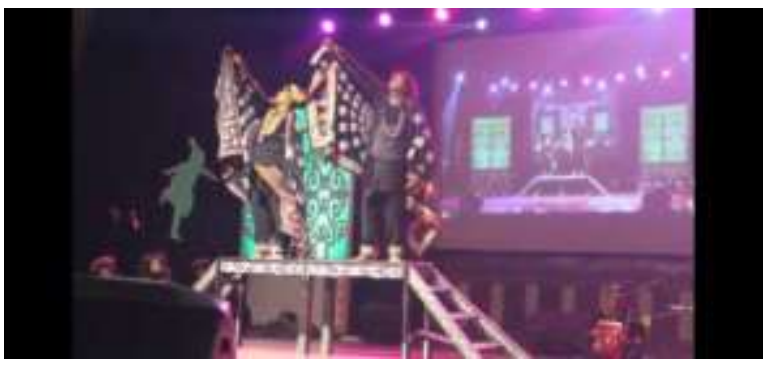

Gambar 1. Penari Dan Kostum pertunjukan PKA ke 7 (Sumber: Petriana Kobat, 2018)

\section{3). Properti Tari}

Properti tari adalah perlengkapan yang seolah-olah menjadi satu dengan badan penari (Soedars ono, 1978).

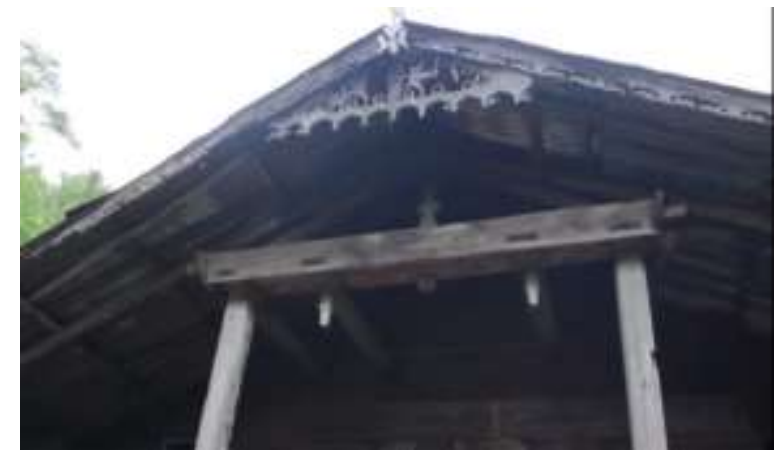

Gambar 2. Tiang Tengah Melintang Tepat di Bawah Atap Disebut dengan Bere, Dahulu Digunakan sebagai Pentas untuk Menari Sebelum Mendirikan Atap

(Sumber: Magfhirah Murni Bintang Permata, 2019)

Properti tari adalah opoh ulen-ulen dan sembilah papan yang dibuat tinggi mengunakan tangga dari sudut kanan dan kiri, seoalah seperti bere numah.

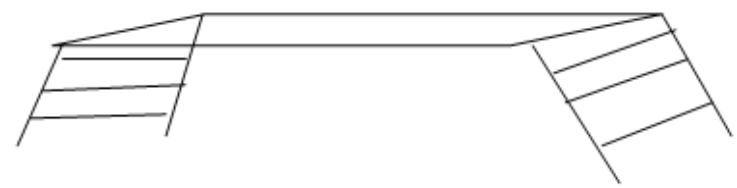

Gambar 3. Properti Tari yang Digunakan sebagai Gambaran Rumah Bere Umah Adat Pitu Ruang (Sumber: Petriana Kobat, 2020)

Properti yang digunakan sebagai sebagai simbol kekokohan sebuah bangunan. Sebilah papan menggambarkan teras rumah dan kedua sisi tangga menggambarkan tangga tinggi yang satu terdapat di depan rumah dan satunya lagi berada di belakang
Gorga : Jurnal Seni Rupa

Volume 09 Nomor 02 Juli-Desember 2020 p-ISSN: 2301-5942 | e-ISSN: 2580-2380

rumah. Keunikan dari Tari Sining salah satu salah satunya adalah medium ungkap yang digunakan properti tarinya.

Menurut The Liang Gie sebuah karya seni sebagai ciptaan manusia mempunyai nilai estetik untuk memuas kan suatu keinginan manusia. Nilai estetik karya seni dapat diras akan dari nilai bentuk dan nilai kehidupan di luar s eni y ang mampu diungkapkan dalam sebuah karya s eni. Nilai bentuk dapat dirasakan dari pengamatan inderawi. Melalui bentuk karya tari penghayat dapat mengagumi dan menikmati sebuah keindahan. Nilai kehidupan adalah nilai-nilai dari kehidupan manusia di luar seni yang diteruskan sebagai isi melalui medium ungkap yang digunakan. Nilai kehidupan dapat diungkapkan melalui sebuah rasa yang dibentuk dari medium ungkap. Keberhasilan pengungkapan itu akan menimbulkan kepuasan batin manusia (Gie, 1976).

\section{Pembahas an}

\section{1). Nilai Bentuk}

Nilai bentuk Tari Sining dapat dirasakan dari ciri-cin sifat benda berbagai aturan-aturan dan teknik-teknik dalam melakukannya. Aturan dan teknik digunakan untuk mencapai kualitas pengungkapan rasa dalam mewujudkan isi yang ingin diungkapkan. Tari Sining memiliki kerumitan, yang dapat dirasakan dari aturan dan teknik yang dibutuhkan dalam proses pengungkapan rasa melalui medium ungkapnya dan geraknya.

Setiap motif gerak yang digunakan dalam Tari Sining memiliki kerumitan, karena adanya aturan-aturan y ang telah ditentukan. Aturan-aturan itu d apat dilihat dan dirasakan melalui bentuk gerakan kaki yang memiliki kerumitan selalu parerel dan sering menjijit, posisi atau tempat yang dilakukan dengan arah seimbang, dan proses perpindahan yang telah ditentukan yang hanya berarah dan berputar ke arah kiri. Didalam setiap motif gerak juga sudah memiliki struktur yang ditetapkan. Struktur itu dapat dilihat dan dirasakan dari bagaimana cara mengawali motif gerak, kemudian diikuti gerak berikutnya, dan bagaimana cara mengakhiri pelaks anaan motif gerak itu. 


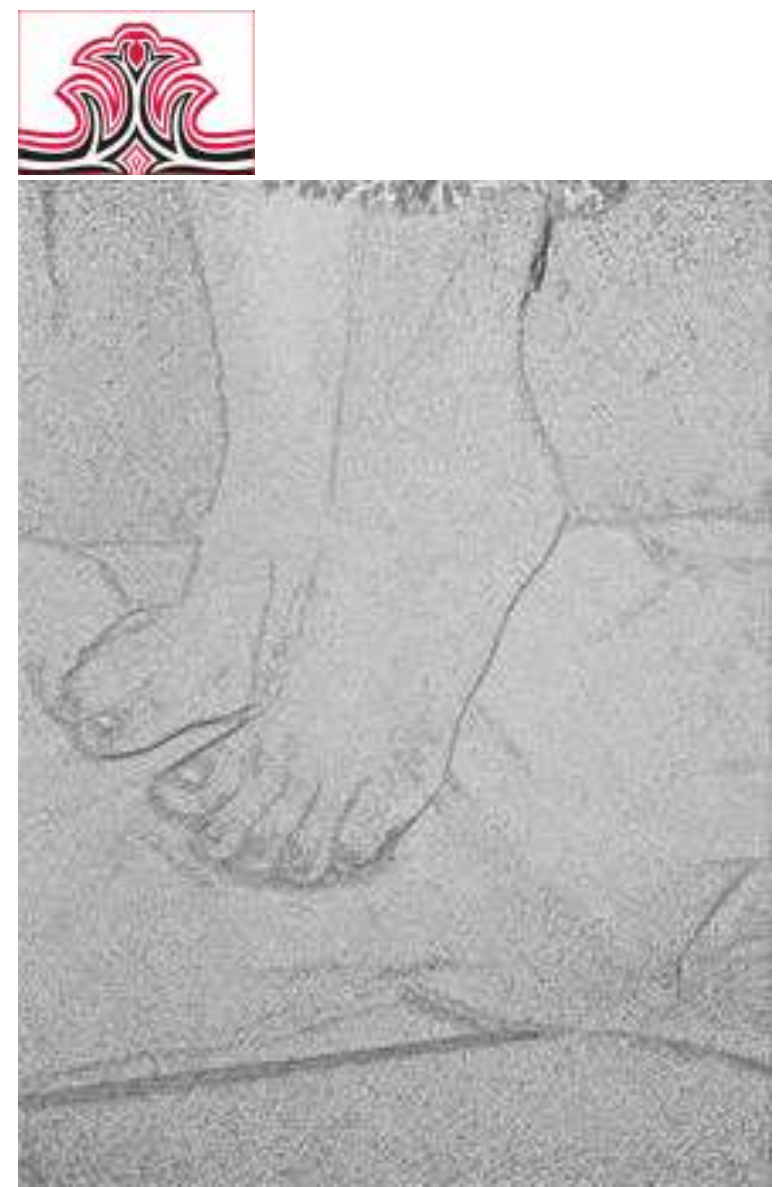

Gambar 4. Tehnik Gerak Jinjit yang Cenderung Dilakukan dari Awal hingga Akhir Pertunjukan Tari Sining.

(Sumber: Magfhirah Murni Bintang Permata, 2020)

Setiap pelaksanaan motif gerak Tari Sining memiliki teknik. Teknik- teknik tersebut digunakan untuk mencapai ketepatan wujud dari motif gerak, sehingga mampu mengungkapkan rasa.Teknik yang dimaksud berupa cara melakukan gerak dan pengaturan tempo gerak supaya sesuai dengan irama gegedem (gendang). Hasil dari penguasaan teknik dalam melakukan setiap motif gerak yang sesuai dengan irama gegedem dan mantra, akan menimbulkan kemantapan rasa Tari Sining.

Gengedem dan semua alat musik tradisional yang digunakan pada Tari Sining memiliki kerumitan sendiri. Kerumitan tampak dengan dibutuhkannya kemampuan mendalam para pemain musik untuk menyajikan menyatukan harmoni musik dan melakukan syair/ mantra dalam Tari Sining.

Kualitas Tari Sining dapat juga dapat dirasakan dari kesatuan, kerumitan, dan variasi medium ungkap pengunaan property yang digunakan. Elemen-elemen pembentuk Tari Sining memiliki kesatuan, sehingga bisa mencapai tataran kualitas ras a yang dalam. Tarisining memiliki variasi yang dapat dirasakan ada pada motif gerak, karawitan tari, dan tata busana yang digunakan. Variasi medium ungkap itu dapat memberi kesan dinamis sehingga tidak monoton.
Gorga : Jurnal Seni Rupa

Volume 09 Nomor 02 Juli-Desember 2020 p-ISSN: 2301-5942 | e-ISSN: 2580-2380

\section{2). Nilai Kehidupan}

Tari Sin ing memiliki nilai estetik karena di dalamnya mampu mengungkapkan nilai-nilai kehidupan. Menurut Dharsono Sony Kartika, nilai-nilai yang ada dalam sebuah karya seni (tari) dipengaruhi pandangan, gagasan, pijakan, dan latar belakang budaya masingmasing daerah (Kartika, 2007).

Nilai-nilai yang terkandung pada Tari Sining dipengaruhi oleh pandangan, pijakan dan gagasan masyarakat Gayo saat mendirikan bangunan yang dilakukan secara bergotong royong. Mulai dari pencarian bahan rumah hing ga rumah berdiri kokoh. Sining adalah salah satu taritradisional yang ada pada mas yarakat dataran tinggi Gayo. Tari Sining dalam kehidupan berbudaya mas yarakat gayo digelar dalam dua prosesi adat yang sakral kedua prosesi tersebut adalah sebagai tarian prosesi dalam rangka membangun tempat hunian (rumah), yang ditarikan secara berpasangandan sebagi tarian prosesi upacara memandikan raja dalam rangka melantik pemimpin baru yang ditarikan secara tunggal (Fajiah. 2018).

Tari sining sebagai salah satu media ungkap rasa syukur penebus rasa lelah, karena Tari Sining hidup dan berkembang di lingkungan masyarakat Gayo.

Nilai-nilai kehidupan Tari Sining dipengaruhi pandangan, pijakan dan latar belakang budaya mas yarakat Gayo dan bangunan Umah Pitu Ruang sebagai tempat pertunjukan tarinya. Hal itu disebabkan karena Umah Pitu Ruang sebagai memiliki otoritas estetis pada Tari Sining, sehingga mempengaruhi kemantapan estetik Tari Sining, baik dari bentuk maupun isi yang diungkapkan. Tari Sining pada jaman dahulu memiliki otoritas estetis terhadap Tari Sining pada saat ini. Karena Tari Sining sudah berada pada wilayah yang baru, yaitu dapat disaksikan pertunju kannya di atas pentas dan dapat dipentaskan di luar memberikan kesan rasa senang pada tiap penampilannya.

Nilai kehidupan dan pesan sosial terhadap masyarakatnya memilki nilai kekerabatan, gotong royong, kerja keras, rasa syukur hingga watak pemimpin di dalam rumah yang tergambar dari raut penari yang tegas, kuat dan adil. Meminta ijin dalam segala hal terhadap pemilik tempat dalamkepercayaan dahulunya dan meminta izin pada tuhan. Bersifat intuitif dan kontemplatif yang secara terus menerus tertuju pada sasaran pengenalan diii, penyatuan diii dengan Tuhan (teosentris) dan jagad raya (kos mosentris), serta mawas diri yang tulus (Mangundiharjo, 2014b). Hal 
itu dapat dirasakan dari rasa sajian Tari Sining pada saat awal pembuka, mantra dan saaat menaiki bere numah atau pada saat ini saat menaiki properti tari. Dalam setiap kemasan Tari Sining menjadi salah satu bagian budaya Gayo. Kebudayaan ju ga berfun gsi menentukan norma untuk berprilaku yang teratur serta meneruskan adat dan nilai-nilai kebudayaan. Tari Sining memiliki nilai dan pesan yang terkandung di dalamnya dari bagian bentuk penyajian tari menjadi ciri khas dan budaya mas yarakat Gayo sendiri, mulai dari, kostum gerak, properti, alat musik iringan, dan syair yang ada di dalam tari sining menjadi hal penting yang harus diketahui agar sesuai dalam bentuk penyajian saat pertunjukaannya.

Tari Sining juga berisi harapan dan cita-cita masyarakat terhadap raja. Di dalam Tari Sining terdapat pesan moral, yang diungkapkan melalui medium ungkap. Pesan moral itu merupakan salah satu cara untuk mencapai harapan dan cita-cita raja. Pesan moral Tari Sining adalah memiilki kekuatan, namun tetap dalam keadaan baik bukan terpecah belah, hanya menimbulkan perpecahan, maka meskipun memiliki kekuatan yang hebat, lebih baik menjalin kebersamaan, karena dengan kebersamaan akan mempermudah untuk mencapai ketentraman, kesejahteraan, dan kemulyaan hidup. Melalui bentuk garap Tari Sining mengungkapkan pesan moral itu, untuk menuntun masyarakatnya dalam mencapai kedamaian, ketentraman, dan kesejahteraan hidup. Kedamaian, ketentraman, kesejahteraan hidup merupakan harapan dan cita-cita dari seorang masyarakat raja terhadap masyarakat terkait kepada penghuni rumah sebagai seorang pemimpin.

Tari Sining merupakan tari yang masuk dalam golongantari mimtif, Tari Sining menggunakan kulcapi Gayo dengan nada-nada (alunan-alunan lagu) yang menimbulkan rasa nikmat hingga menjadi khas nuasa musik Gayo tersusun secara baik, dapat menimbulkan rasa indah dan halus, serta dapat membawa jiwa manusiakesuas ana luhur tradisiCayo.

Tari Sining merupakan salah satu simboldari dua sisi yang saling bersamaan y aitu baik dan s aling peduli. Tari Sining adalah karya tari yang disajikan tergolong pada jenis tari duet pada saat ini namun dahulu tarian ini tidak dibatasi untuk penari yang dilakukan dengan spontanitas baik penonton dan pemusik diperbolehkan untuk menari.

Bentuk gerak, tata rias dan busana yang sama, serta konflik yang seimbang (tidak ada yang kalah dan menang) pada Tari Sining, mampu mengungkapkan
Gorga : Jurnal Seni Rupa

Volume 09 Nomor 02 Juli-Desember 2020 p-ISSN: 2301-5942 | e-ISSN: 2580-2380

keselarasan dan keseimbangan (equilibrium). Pengendalian diri dapat dirasakan setelah terdapat konflik/klimkas yang seimbang, kedua penari berputar, menaiki papan mundur, kemudian s aling respon berhadapan, menghentak kaki, dan memainkan opoh ulen-ulen, harmonis. Kesatuan yang utuhdapat dilihat dan diras akan dari bentuk gerak dan arah hadap yang sama, serta bentuk pola lantai yang melingkar dan simetris.

Pola lantai Tari Sining memiliki pola dasar yang melingkar dan simetris. Pola lantai melingkar ke arah kiri yang dibentuk oleh sepasang penari (sining) mampu mengungkapkan keseimbangan dan kesatuan alam dari dua sisi yang berlawanan, karena memiliki bentuk y ang menyerupai simbol manuk uwo dan manuknunguk. Manuk uwu dan nunguk adalah dua jenis burung yang berbeda adalah sebagai beda namun tetap dalamdapat saling bekerjasama melalui kerjasama amka akan terwujudnya sebuah tujuan, simbol walau dalam simbol dari baju dan ulen-ulen memiliki makan dan warna khas dari daerah Gayo. Berhadapan dengan seimbang laksana roda yang berputar kes eimbangan, y ang harus dilakukan kompak dan bersamaan tanpa berat sebelah hingga membutuhkan kerjasama saling peduli dalam gerak. Simbol ini merupakan lambang penyadar akan hakikat kehidupan manusia tentang sifat yang telah menjadikodrat keilahian manu sia yaitu kebaikan dan keburukan (Kresna, 2010). Dalam Tari Sining tetap memilih jalan kebaikan dan kearjasama bahwa hidup tidakakan seimbang jika dilakukan sendini.

Tari Sining merupakan simbol pengendalian diri dan keseimbangan alamdalamkosmologi Gayo. Kedua penari Tari Sining merupakan gambaran kesimbangan alam s ama halnya seperti tari yang terdahulu Tari Guel yang menjadikan alam sebagai sumber inpirasi geraknya, alam pula sebagai guru terciptanya Tari Guel pada masy arakat Gayo. Menjadikan apa yangada di dalam sebagai alat musik pengiring tarinya. Begitu halnya dengan Tari Sining y ang nama tari ini juga ada apa unsur gerak di dalam Tari Guel.

Tari Sining juga berakar dan terinspirasi dari alam, keseimbangan antara alamdan penghuni alamgerakan mimitif hewan, pengambilan bahan rumah dari alam, keseimbangan penari dan poros putaran yang hanya dilakukan ke sebelah kiri seperti poros perputaran bumi.

Tari Sining adalah tari rakyat, yang pada sebelumnya dipertunjukan di alam terbuka, rumah panggung dan saat ini diatas panggung dengan pola lantai me lingkar 
dan horizontal antar kedua penari baik saat berada di atas properti maupun sebaliknya, seperti satu penari berada di bere ni umah (bere digambarkan di atas papan) sisi kiri dan satu penari berada di sisi kanan bawah, simetris pada Tari Srimpi Pandhelori.

Masyarakat gayo memiliki beberapa konsep kehidupan yang diungkapkan dalam Tari Sining. Konsep kehidupan itu merupakan nilai-nilai kehidupan masyarakat Gayo yang menjadi sebuah pandangan, dan pijakan kebiasan dan bu day a masy arakat Gayo dalam menjalani kehidupan di dunia ini. Nilai-nilai kehidupan masy arakat Gayo yang diungkapkan dalams eni tertuang dalam Tari Sining tentang kerjasama dan kekeluargaan serta ungkapan rasa syukur, tetap memegang etika.

Etika mempunyai sifat yang sangat mendasar yaitu sifat kritis, etika mempersoalkan norma-norma y ang dianggap berlaku, menyelidiki norma-norma itu. Bahwa etika adalah tingkah laku manusia menganai baik atau buruknya sifat seseorang dalam kehidupannya sebagai mahkluk sosial dan bagaimana manusia bertindak (Saadah,2013). Dalamkes enian Gayo terdapat etika dan beberapa kata yang tidak boleh diucapakan pada saat pelantunan s eniman digolongkan tidak beradab dan tidak boleh di ucapkan pada saat pelantunan apabila menyebutkan kata-kata berikut:

1. Jis adalah perbuatan y ang dapat melukai atai orang lain

2. Jengkat adalah perkataan yang menyakiti atau menyinggung hati dan perasaan oran lain.

3. Kemali adalah perbuatan, tindakan atau perkataan yang melanggar ketentuan aturan adat yang bahsanya kembali kepada si pelaku.

4. Sumang perkataan y ang melanggar aturan adat dan dampaknya dengan dosa dalams yariat is lam. (Joni, ed. 2017).

Tari Sining mengangkat dua gambaran dari alam berserta isi, yang mana keduanya harus berimbang agar alam tetap terjaga dan menjadikan alam sebagai sahabat, gambaran Tari Sining bercerita dengan bermula, dari keberangkatan sekolompok laki-laki dewasa yang mencari kayu terbaik di hutan untuk dijadikan sebagai bahan pokok pembuatan rumah di mulai dari pemilihan kayu kecil hingga sampai pada peletakan reje tiang saat membangun rumah, perjalanan di tengah hutan dengan melihat dua ekor burung manuk owo dan manuk ungguk menjadikan ins pirasi sehingga pada saat selesai pendirian rumah, mereka mengungkapkan apa yang mereka lihat ke dalam Tarian Sining, dan melihat dua pasang ekor yang
Gorga : Jurnal Seni Rupa

Volume 09 Nomor 02 Juli-Desember 2020 p-ISSN: 2301-5942 | e-ISSN: 2580-2380

berbeda menggambarkan perbedaan watak dari tiap orang yang ada di dalam kelompok bukanlah satu masalah yang bisa menghalangi segala tujuan ingin dicapai bersama.

Namun perbedan lantas menjadi hal yang indah dan beragam hingga dapat menjadi satu ide kaya jika dapat disatukan dengan baik layaknya gerak burung uwo dan unguk yang berbeda jenis namun beberapa gerakkan mencoba untuk tetap sama, sesekali tampak berbeda memunculkan khas karakter masing-masing namun tetap saling menjaga satu sama lain agar tetap seimbang tetap saling adil, tanpa harus ada yang mencolok satu sama lainnya, terlihat pada pola yang terus dijaga horizontal oleh penari, kerjasama adalah hal utama yang dibutuhkan dalam pekerjaan.

Tari Sining adalah salah satu tarian berasal dari daerah Gayo Kabupaten Aceh Tengah. Tarian ini pada tahun 2020 telah ditetapkan menjadi salah satu warisan budaya tak benda (WBTB). Upaya tenus dilakukan revitalisasi agar tarian ini menjadi salah satu upaya, agar tarian ini kembali dikenal oleh mas yarakat, dalam perjalanan revitalisasi salah satu sanggar pertama yang merekonstruksi gerak Tari Sining adalah sanggar Kuta Dance, yang berada di Kabupaten Aceh Tengah.

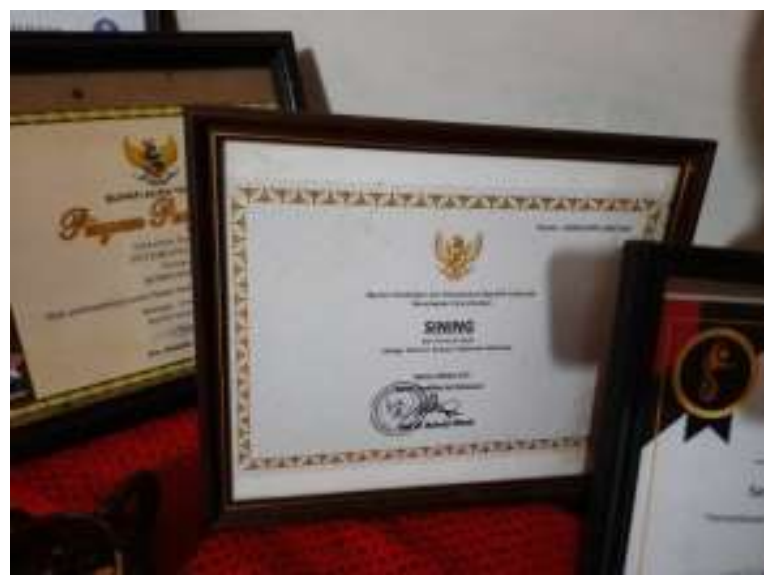

Gambar 5. Sertifkat Tari Sining sebagai Salah Satu Tari Warisan Budaya Tak Benda (WBTB).

(Sumber: Magfhirah Murni Bintang Permata, 2020)

\section{KESIMPULAN DAN SARAN}

\section{Kesimpulan}

Pela Tari Sining adalah salah satu karya tari yang berasal dari daerah Gayo Kabupaten Aceh Tengah, namun terdapat teknik pelaksanaan gerak baru yang telah direvitalisasi kemudian direkontuksi oleh sanggar Kuta Dance Takengon. Gerakkan-gerakan yang hadir dalam Tari Sining adalah gerakan-gerakan mengadopsi gerakan dari manuk uwo dan manuk ungguk, gerak dan 


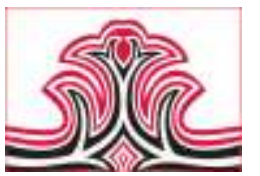

properti juga tempat pertunjukannya menyebabkan Tari Sining memiliki karaktenistiktersendiri, ke mu dian dis ebut dengan n ama Tari Sining.

Tari Sining memiliki nilai es tetik daribentuk maupun isi yang menjadi satu kesatuan. Nilai bentuk Tari Sining dapat dirasakan dari kesatuan, kerumitan, dan kualitas yang dimiliki. Isi tari sining adalah nilai-nilai kehidupan mas yarakat Gayo. Nilai-nilai kehidupan itu mampu diungkapkan melalui lambang-lambang sensa mediumungkap Tari Sining. Nilai-nilai kehidupan masy arakat Gayo yang diungkapkan dalam tari ters ebut adalah nilai kekerabatan, kekeluargan dan nilai keseimbangan, serta pengendalian diri.

\section{Saran}

Tari Sining merupakan salah satu wawasan baru untuk masyarakat Aceh khususnya masyarakat Aceh bagian dataran tinggi Gayo, dalam upaya revitilasi menjadikan tarian ini menjadi salah satu WBTB bukan hal yang mudah, banyak unsur terdapat unsur estetika lebih sehingga tarian ini menjadi salah satu tari yang pemah punah namun dapat diterima kembali oleh mas yarakat, adapun beberapa saran bagi pemerintah khusunsya masyarakat Gayo, agar lebih mengenal, mempelajari, meneruskan apa yang telah diupayakan oleh beberapa seniman sehingga tarian semakin mudah berekembang dan dapat kenal oleh masyarakat serta generasi muda dapat mengalami pengalaman emperis dari praktik tarinya.

\section{DAFTAR RUJUKAN}

Fajiah, Nur, Selain, Rida Safuan \& Hartati, Teungku. (2018). Sining dalam Konteks Kebudayaan Gayo. Jurnal Ilmiah Mahasiswa Program Studi Pendidikan Seni Drama, Tari dan Musik Fakultas Keguruan dan Ilmu Pendidikan Unsyiah, 3(3), 299-310.

Gie, The Liang. (1976). Garis Besar Estetika. Yogyakarta: Penerbit Karya.

Hadi, Y. Sumandiyo. (2003). Aspek-aspek Dasar Koreografi Kelompok. Yogyakarta: Manthili.

Joni, (ed.). (2017). Meretas Seni dan Budaya Gayo. Aceh Tengah: Elmarzaki Publisher.

Kartika, Dharsono Sony. (2007). Budaya Nusantara, Kajian Konsep Mandala dan Tri-Loka terhadap Pohon Hayat pada Batik Klasik. Bandung: Rekayasa Sains .

Kresna, Ardian. (2010). Semar dan Togog Yin Yang dalam Budaya Jawa. Yogyakarta: Narasi.

Manan, Abdul, et.al (ed.). (2017). Revitalisasi Seni yang Hampir Punah: Landoq Sempot, Rapai Guriempeng, Tari Sining Gayo, Tari Lawet. Jakarta: Kemendikbud.
Gorga : Jurnal Seni Rupa

Volume 09 Nomor 02 Juli-Desember 2020

p-ISSN: 2301-5942 | e-ISSN: 2580-2380

Mangundiharjo, Slamet. (2014a). Barongan Blora Menari di Atas Politik dan Terpaan Zaman. Surakarta: Citra Sains.

- (2014b). Garan Joged Sebuah Pemikiran Sunarno. Surakarta: Citra Sains.

Moleong, Lexy J. (2008). Metodologi Penelitian Kualitatif, Bandung: PT. Remaja Ros dakarya.

Parker, De Witt H. Humardani, SD (terj). (1979). Dasar-Dasar Estetika. Sub Proyek ASKI, Proyek Pengembangan IKI.

Prihatini, et.al. (2007). Ilmu Tari Joged Tradisi Gaya Kasunanan Surakarta. Surakarta: ISI Press.

Saadah \& Rahma, Sitti. (2013). Es tetika dan Etika Tari

Guel pada Masyarakat Gayo Kabupaten Aceh Tengah. Jurnal Pendidikan Bahasa dan Seni Unimed, 1(1), 1-13.

Simatupang, Lono. (2013). Pergelaran: Sebuah Mozaik Penelitian Seni Budaya. Yogyakarta: Jalasutra.

Soedarsono, R.M. (1978). Diktat Pengantar Pengetahuan dan Komposisi Tari. Yogyakarta: ASTI Yogyakarta. 